\title{
Economics of Coalbed Methane in North West Spain
}

\author{
Jose A. Gutiérrez, Raquel García \\ Campus de Vegazana, Universidad de León, León, Spain \\ Email: jagutbr@unileon.es
}

How to cite this paper: Gutiérrez, J.A. and García, R. (2018) Economics of Coalbed Methane in North West Spain. International Journal of Clean Coal and Energy, 7, 21-38

https://doi.org/10.4236/ijcce.2018.72002

Received: April 1, 2018

Accepted: May 25, 2018

Published: May 28, 2018

Copyright $\odot 2018$ by authors and Scientific Research Publishing Inc. This work is licensed under the Creative Commons Attribution International License (CC BY 4.0).

http://creativecommons.org/licenses/by/4.0/

\begin{abstract}
Coal during its carbonization process produces a gas. This gas, mainly formed by methane, can be used. The use of CBM (Coal bed methane) as an energetic resource is not much known in Spain. This work is the first step to enhance the development of this resource in Castilla y León. A theoretical review and a state of the art description have been carried out, taking into account all the factors that can influence in the development of a CBM project. Then CBM resources have been quantified by Castilla y León accurately for every coal bed. After that, technical feasibility has been used to evaluate total amount of gas that can be recovered. The last step was to evaluate economic feasibility to know how much gas could be economically profitable. This paper covers the economic factor and exploitation options of CBM in Castilla y León, considering technical parameters together with costs and economic requirements for the tow most promising areas in north-west Spain. The main findings include that a CBM system would be feasible in Guardo-Barruelo, however, the economic feasibility will be limited to long operation time of the wells and an increase of the prices of natural gas. In North Leon, the results show a high profitability even under low natural gas prices.
\end{abstract}

\section{Keywords}

Coalbed Methane, Coal Feasibility, Coal Economics, Unconventional Natural Gas

\section{Introduction}

The gas contained in coal layers is an important energy resource capable of supporting the growing increase in energy demand. This gas contained in the coal is a byproduct of the process of maturing it, as will be detailed later, which can be increased later due to different mechanisms. Initially, this gas was considered 
dangerous, so its concentration was reduced to increase safety in the mines. At present, this vision has changed and, far from diluting it, the maximum use of its energy potential is pursued.

The main reaction of methane to obtain energy is oxidation, although there are other reaction characteristics of this chemical compound that give its value for other uses, such as halogenation, pyrolysis or cracking, or nitration.

The energy produced by oxidation of methane is $55.64 \mathrm{MJ} / \mathrm{kg}$ of oxidized methane $\left(33.38 \mathrm{MJ} / \mathrm{Nm}^{3}\right)$.

Under normal conditions, methane is a less dense gas than air so that its emanations accumulate in the upper parts of the mining works. It is also colorless, odorless and flammable.

The programs of financing or subsidy for $\mathrm{R} \& \mathrm{D}$ are varied. National or international financing, both for direct exploitation and for research, can be found. In certain countries, the gas obtained from this source is subsidized, with which the economic viability increases. In the United States, for example, some tax credits were established, while in Germany, it is considered as a renewable energy resource and has a guaranteed remuneration of $6.6-7.7 \mathrm{ct} € / \mathrm{kWh}$, which has favored the investments and has made that currently an installed capacity of $150 \mathrm{MW}$ is available.

The main risk factors in the development of a project of this type are: the capacity of the gas pipeline or the consumption to be obtained, the prices of natural gas, the sale price of the producer's gas and technological knowledge.

The requirements for the viability of a coalbed methane (CBM) project would be those listed below [1] [2] [3] [4]:

- Methane content greater than $7 \mathrm{~m}^{3} / \mathrm{t}$, although areas of $2 \mathrm{~m}^{3} / \mathrm{t}$ are being successfully exploited.

- Appropriate carbon rank.

- High power.

- Possible increase in permeability.

- An anticline or other type of entrapment.

- Joined, fractured and permeable strata.

- Local consumption for small quantities of high-quality gas or infrastructure to evacuate the gas produced.

- Good access for drilling.

- Water produced; Quality and quantity; Low cost of water disposal.

This work will analyze the possibility to extract CBM from Guardo-Barruelo and North Leon basins in Spain in an economic feasible way. Although there are some studies about quantification of CBM in Guardo-Barruelo and North León basins, this economic evaluation has not been performed. This includes all costs of a CBM project (infrastructures, permits, water treatment etc.) compared to the income from selling the novel energy source.

\section{Methodology}

Not all the gas contained, nor all the resources, can be considered as reserves, so 
we will try to differentiate the resources, or total extractable amount of the reserves that can be extracted in a profitable manner based on the local conditions of Castilla y León. Due to the variability of local conditions, four gas evolution scenarios and three profitability rates are proposed to determine the economic viability of the CBM extraction. The data from coal quantity and gas concentration come from available studies of Castilla y León [5] [6] [7].

Once a CBM reserve has been evaluated and the economic viability of the extraction has been proven, the legal uncertainty that exists in many cases for this resource is presented as an obstacle. It is therefore necessary to clearly regulate the rights and obligations of the owners of the concessions, as well as the qualities of the gas obtained.

The CBM extraction has been considered with own funds, without any other type of financing or state, banking, European subsidy, etc. But there could be several alternative sources of funding or subsidy of CBM projects in Castilla $y$ León that are also going to be described. This financing or subsidy will increase the economic viability of the extraction.

The possible sources of financing for a project of this nature, with special mention to those applicable to Castilla y León have been studied, however, they are not included in this report and only own funds are considered. The development costs of a CBM well will be defined for the selected cases. Later, the paths for the recovery of the investment will be defined. Three ROI targets will be defined, starting with the three of own funds. The first one will be an absolute return, for which the well covers the expenses generated by the gas generated, the second will be the one that gives us more profitability than an investment of $4 \%$ per year, and the third will also include the uncertainty of the investment that is considered at $8 \%$. These returns will be calculated for four scenarios of variation in the price of natural gas. A first is in which the price of gas remained constant. The second would contemplate a gas price $25 \%$ lower than the current one. The third and fourth would be made considering an increase of 25 and 50\% of the price of gas respectively. Scenarios studies are shown in Table 1.

\section{Financing}

The development of a CBM project requires a great economic and time investment. The economic viability of a project of this type is difficult to predict, hence the researchers who evaluate the CBM are indecisive and diffuse in their predictions.

Table 1. Gas price scenarios [8].

\begin{tabular}{lccc}
\hline & Price NG & $€ / \mathrm{MWh}$ & $€ / \mathrm{m}^{3}$ \\
\hline Scenario 1 & Reference & 26.413 & 0.2527 \\
Scenario 2 & $-25 \%$ & 21.1304 & 0.2022 \\
Scenario 3 & $+25 \%$ & 33.01625 & 0.3159 \\
Scenario 4 & $+50 \%$ & 39.6195 & 0.3791 \\
\hline
\end{tabular}


Although the existence of gas is demonstrated, the benefits of a CBM project are not safe and, although they are producing significant advances in drilling and modeling techniques, there is no guaranteed methodology to estimate their viability.

The phases of the evaluation of a project would be composed of:

- Collection of public data of the place.

- Conducting surveys.

- Determination of the permeability of the coal where production wells are proposed.

- Performance of a multi-well test, where interferences and flows between wells would be evaluated.

- Data entry in a model for the valuation of the reserve.

- Predictions of production for the projected field development.

The importance of the number of pilot wells is relative, since they will never be significant enough. The number of wells needed to have some certainty in the investigation has not been defined. Better how many more are made but they are expensive.

The approval of the project at the national level may be simpler if it is presented as a resource for increasing the security in the mines in the local administration, which is usually more accessible, and will take into greater consideration the socio-economic value of the project.

The feasibility analysis will be a function of the analysis of training and economic analysis. Boyer said that the problems to demonstrate the viability of the CBM, are due to the low reliability in the evaluation of the potential [9]. The evaluation of reserves must include:

- Prediction of production: water, gas, losses, etc. From these production data required to request financing for the project would be the field data available from the previous studies. The different productions of neighboring wells must be evaluated, since the production is very variable.

- Economic forecast, where they will be described: gas prices, taxes, applicable interests, discount factors, etc.

- Parameters that influence the cost: investment, operating costs, transport costs, etc.

With these predictions, cash flows have to be processed and from there deducing the economic criteria to evaluate the viability of the project: pay-back, IRR and unit cost of methane $\left(€ / \mathrm{m}^{3}\right)$.

The Pay-back for each well will be obtained from the investment amortization time (drilling, completion and operation). The benefits are equal to gross income minus taxes.

The internal rate of return (IRR) is a parameter that is used to measure the efficiency of the investment. Corresponds to the rate of return for which the current value of the cash flow of an investment is equal to the current value of the entire investment. 


\section{Economic Feasibility of Proposed Wells}

\subsection{Costs of a CBM Well}

In this section you will define the annual costs of a CBM well. Up to 20 years. The study conducted by the US DOE, United States Department of Energy, "The Economics of Powder River Basin" will be used as a basis [10], costs are shown in Table 2.

From the reference of the drilling costs for 500 and 900 feet respectively, we can obtain the costs of our type drilling of $1000 \mathrm{~m}$. The capital investment costs for the well would be the shown in Table 3 .

The drilling and development costs of the surface installation for a CBM well are set at 240,000 euros. With respect to the cost of operation and maintenance found the values shown in Table 4.

As annual fixed costs we can determine the following, shown in Table 5.

Table 2. Well construction costs [10].

\begin{tabular}{cccc}
\hline Depth (ft) & 500 & 950 & \\
\hline Depth (m) & 152 & 290 & 1.000 \\
\hline Perforation costs & 60.000 & 74.000 & 146.515 \\
\hline Intangibles & 50.000 & 62.000 & \\
Tangibles & 10.000 & 12.000 & 54.943 \\
\hline Well completion costs & 22.500 & 27.750 & \\
\hline Intangibles & 7.500 & 9.250 & \\
\hline Tangibles & 15.000 & 18.500 & \\
\hline
\end{tabular}

Table 3. Capital investment costs for a CBM well [10].

\begin{tabular}{cc}
\hline Concept & Cost $(€)$ \\
\hline Permits & 11,890 \\
Perforation and completion $(1000 \mathrm{~m})$ & 159,685 \\
Water treatment & 20,292 \\
Water disposal & 1189 \\
Electricity & 9829 \\
Gas collection & 34,797 \\
Total & 237,681 \\
\hline
\end{tabular}

Table 4. Operation and maintenance costs of a CBM well [10].

\begin{tabular}{cc}
\hline \multicolumn{2}{c}{ Operation and maintenance costs } \\
\hline Year 1 & $37,452 €$ \\
Years 2 - 4 & $20,189 €$ \\
Year $>4$ & $14,482 €$ \\
\hline
\end{tabular}


Table 5. Annual fixed costs of a CBM well [10].

\begin{tabular}{ccccc}
\hline \multicolumn{5}{c}{ Annual fixed costs $(€ /$ year $)$} \\
\hline Leasing & Management and administration & Water treatment & O \& M expenses & Leasing \\
\hline 15,000 & 9000 & 3000 & 10,000 & 15,000 \\
\hline
\end{tabular}

\subsection{Revenue from Extraction of the CBM}

The expected revenues will come from the sales of the recovered gas. Although it is possible to obtain financing, these aids will depend on the body that develops the project, in this study are not going to take into account these incomes derived from the potential financing.

With respect to the price of the CBM, for natural gas the price depends on the market. The market sets a calorific value of the gas at $34.48 \mathrm{MJ} / \mathrm{m}^{3}$, which will be used in the conversion. Due to the variability of the price of gas, revenues may fluctuate significantly, so a sensitivity analysis of the feasibility of the project is carried out, with four possible scenarios based on this price variability of the gas. A first is in which the price of gas remained constant on $26.413 € / \mathrm{MWh}$ or $0.2527 € / \mathrm{m}^{3}$. The second would contemplate a gas price $25 \%$ lower than the current one. The third and fourth would be made considering an increase of $25 \%$ and $50 \%$ of the price of gas respectively.

\section{Methodology for Determining Each Parameter}

The objective of this chapter is to establish initial parameters of the reserve in order to know its production. CBM production depends on several parameters. In this section we will detail the methodology used to determine them.

A methodology for the initial estimation of CBM resources and reserves easily extrapolated has been developed. This methodology will serve to determine in what amount the parameters of the reserve should vary to obtain the return on investment. The calculations have been made in Anglo-Saxon units, due to their greater development in calculation methods and they have been converted to units of the international system later for a better compression. It will consist on the determination of:

- Coal saturation.

- Absolute permeability.

- Porosity, compressibility and pore volume.

- Calculation of gas production.

\subsection{Coal Saturation}

Once the drilling point has been defined, the immediate analysis of the coal is taken and its rank determined. The analysis is corrected in ash, for an ash content of $15 \%$, which is the estimated content in the layer. The analysis of ash-free dry coal, which will be used in later calculations, is also corrected.

Once this is done, the gas content of the target layer is extracted and expressed 
both in gross ton, tb, $(15 \%$ ash) and per dry ton free of ash or pure ton (daf or tp).

Knowing the depth and the coal rank are known, we can estimate the maximum theoretical gas amount from the type adsorption isotherms of the Eddy diagram. This is shown in Figure 1. By comparing the maximum capacity of adsorption with the gas content, we can know the degree of saturation of the coal.

\subsection{Calculation of Maximum Desorbed or Recovered Gas}

The next stage determines the calculation of the initial pressure of the matrix and of the fractures. The initial pressure of the fractures is established based on the depth, the initial pressure of the matrix is related to this. From the Eddy curve, a minimum desorption pressure is estimated, which will be the pressure of the fractures at which the coal will begin to desorb gas.

The final pressure of the well, and therefore of the fractures, is set at $75 \mathrm{psi}$ as an operating parameter. Again entering the Eddy curve we can know the amount of gas not desorbed, and by difference with this, the percentage of gas recovered maximum.

\subsection{Absolute Permeability}

To determine the absolute permeability we will use the equation of Gray [12] that relates cleats and permeability:

$$
K=\frac{\left(1.013 \times 10^{10}\right) \cdot b^{3}}{12 \cdot s}
$$

Equation (1): Gray's Equation. Where:
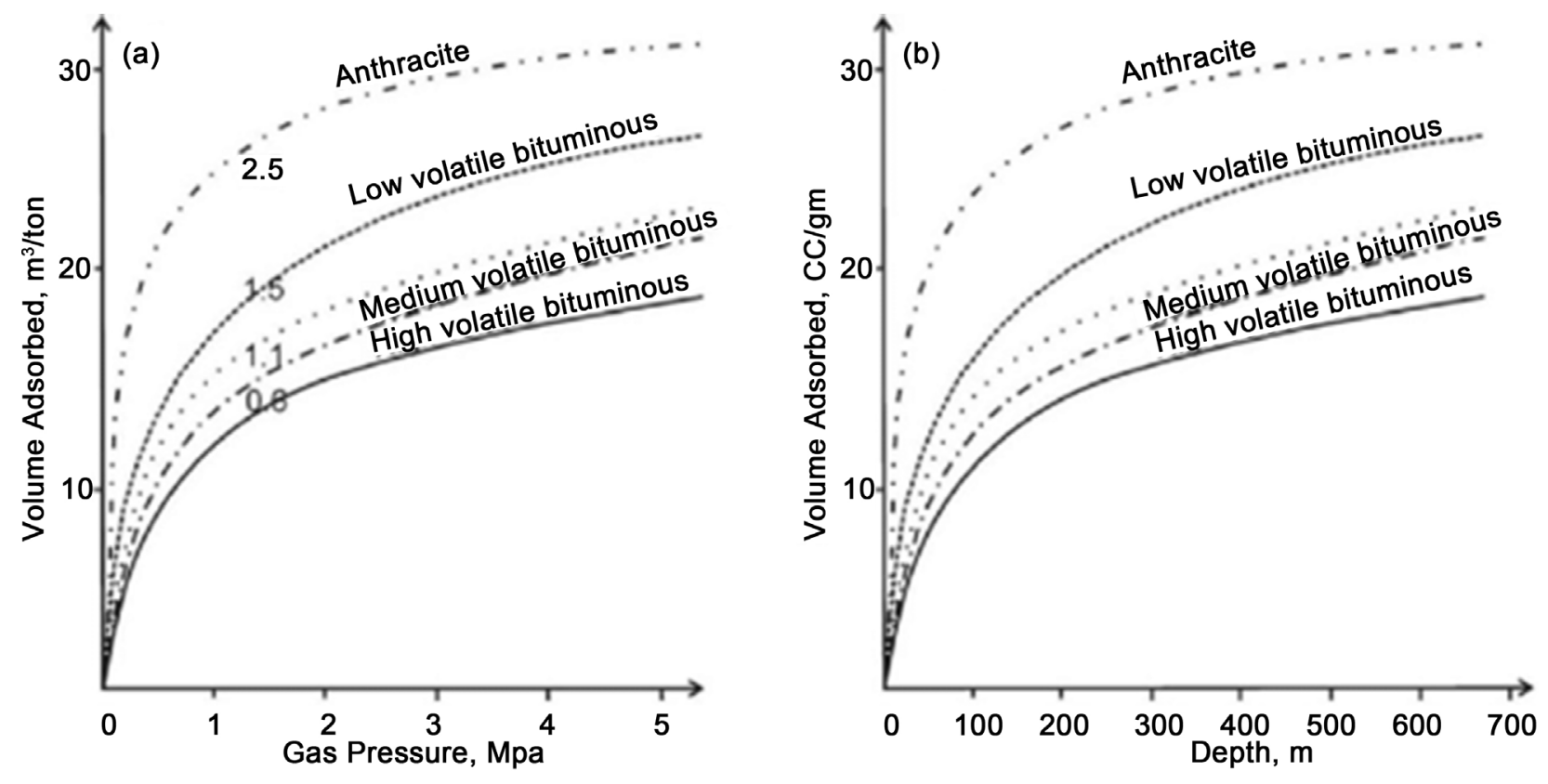

Figure 1. Eddy diagram for maximum gas adsorption [11]. 
- $b$ : width of cleats $(\mathrm{mm})$

- $s$ spacing of cleats $(\mathrm{mm})$

- $K$ : permeability $(\mathrm{mD})$

In order to determine the characteristics of the cleats, the following tables and graphs will be used, as well as articles about the spacing of cleats in the coal [13] [14] [15] and they are contrasted with data from other similar carbons and with results from various research articles on char properties. Table 6 shows cleats spacing depending on coal rank. Figure 2 shows relation of permeability with cleats number and spacing.

\subsection{Porosity, Compressibility and Pore Volume}

The porosity will be estimated according to the range based on the analysis of the Gas Research Institute [16].

\subsection{Well Spacing}

Well spacing is manifested as a key factor for the economic viability of the reserve. The well spacing is estimated according to the properties of the reserve, with permeability being the most important parameter. The upper and lower

Table 6. Spacing of cleats depending on coal rank [14].

\begin{tabular}{cc}
\hline Coal rank & Cleats spacing $(\mathbf{c m})$ \\
\hline Sub-bituminous & $2-15$ \\
Bituminous high in volatiles & $0.36-2$ \\
Bituminous medium and low volatile & $<1$ \\
\hline
\end{tabular}

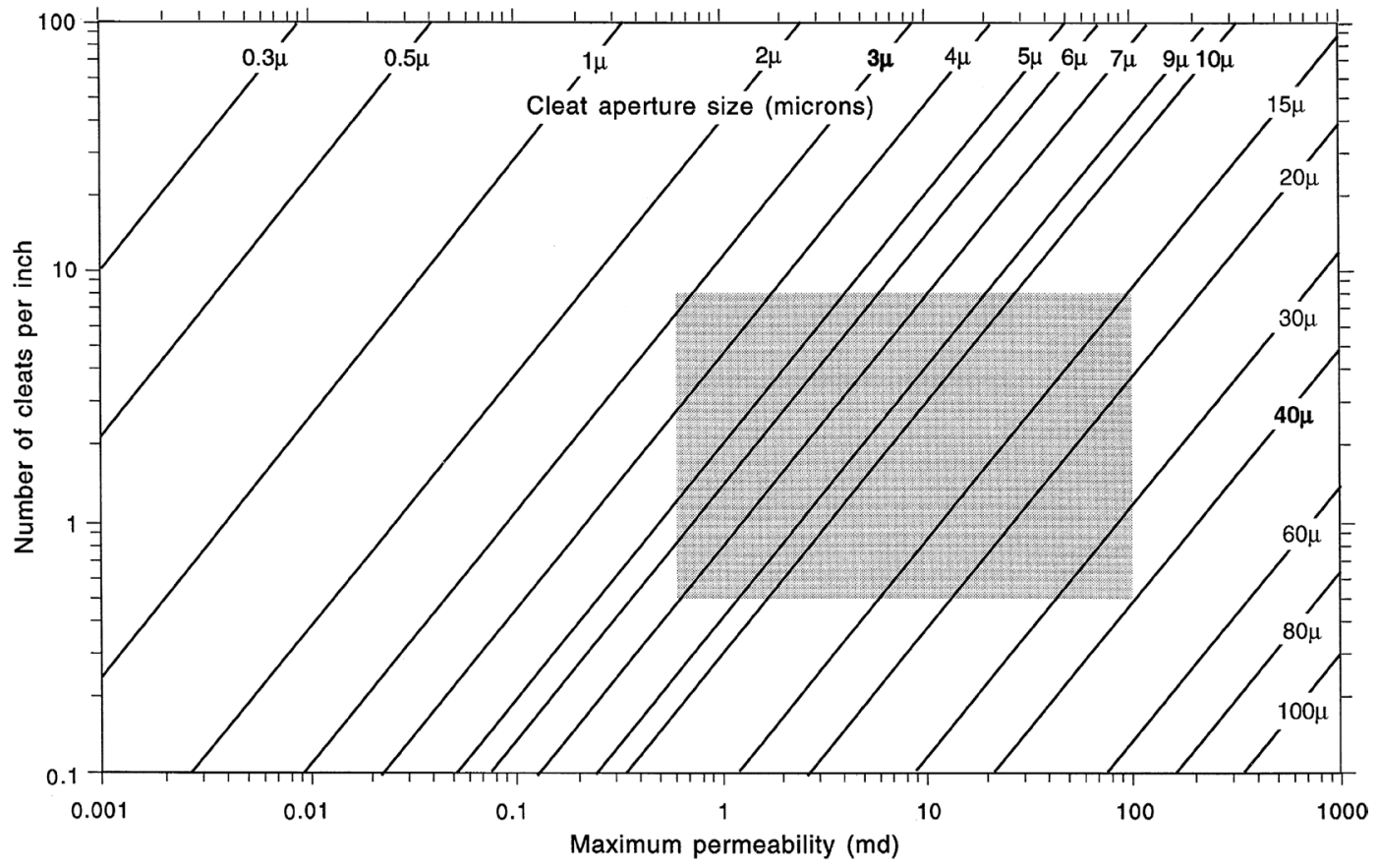

Figure 2. Relation permeability, cleats number and cleats spacing [13]. 
limits are set at 800 and $500 \mathrm{~m}$, or 120 and 60 acres respectively, surfaces that are considered appropriate for CBM exploitation.

\section{Estimation of Gas Production}

The estimation of gas production over time is carried out by developing the curves defined by García Arenas for the Department of Petroleum and Natural Gas Engineering of West Virginia [17]. They describe a curve model from two dimensionless parameters, $t_{D}$ and $q_{D}$, which thanks to their dimensionless condition are able to simulate the production of gas in any basin. Figure 3 shows the typical CBM production curve in logarithmic scale. The equations used are Equations (2)-(4).

This method has been proven by specific simulation software for CBM, such as the CMG GEM, with good results.

$$
q_{D}=\frac{q}{q_{\text {peak }}}
$$

Equation (2) a dimensional peak flow [17]

$$
t_{D}=\frac{t \cdot q_{\text {peak }}}{G_{i}}
$$

Equation (3) a dimensional time factor [17] where:

- $q_{D}$ : dimensionless peak flow.

- $q$ : actual flow.

- $q_{\text {peak }}$ : peak or maximum flow.

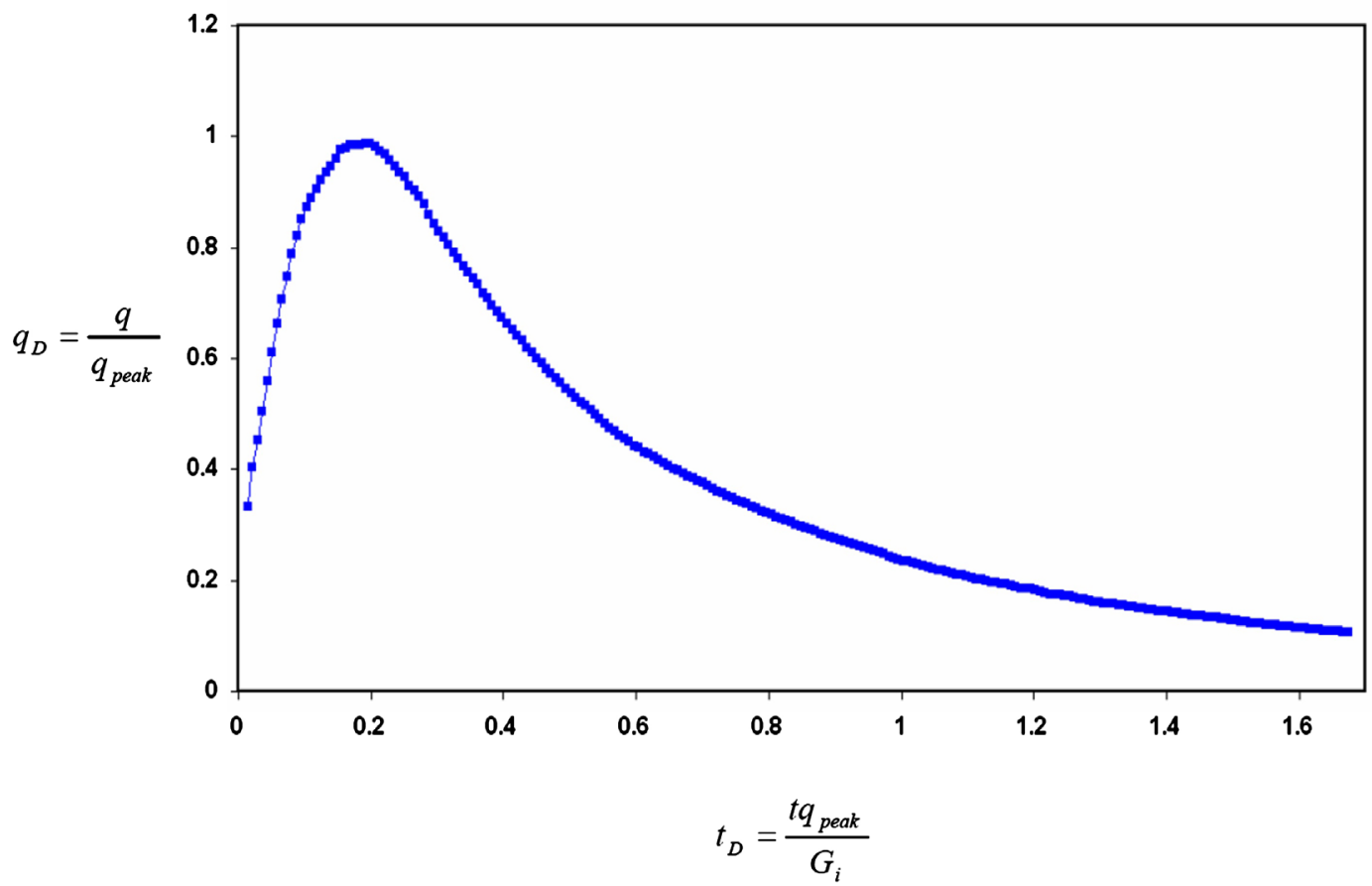

Figure 3. CBM production curve in logarithmic scale. In abscissas td, in ordinate qd. [17]. 
- $t_{D}$ : dimensionless time factor.

- $t$ :time in days.

- $G_{i}$ : amount of gas in place.

$G_{i}$ is determined multiplying coal quantity per coal gas contents. The greatest difficulty lies in the estimation of peak flow. It will come de-terminated by:

$$
q_{\text {peak }}=q_{D} \cdot k \cdot h \cdot\left(P_{m}-P_{w f}\right)
$$

Equation (4) Peak flow [17]

where:

- $k$ : permeability.

- $h$ : height of coal layer.

- $P_{m}$ : initial pressure of the matrix.

- $P_{w i}$ initial pressure in the fracture system.

We have all the data of previous stages except the $q_{\text {peak }}$, which is obtained through the following Figure 4.

\section{Technical Parameters for Each Zone}

The values of the parameters calculated here are estimates and based on available data. These values have to be updated with field values, when drilling and well tests are carried out, in order to adapt the model to reality once real data are extracted during the drilling and finishing of the wells.

It will consist of the following phases:

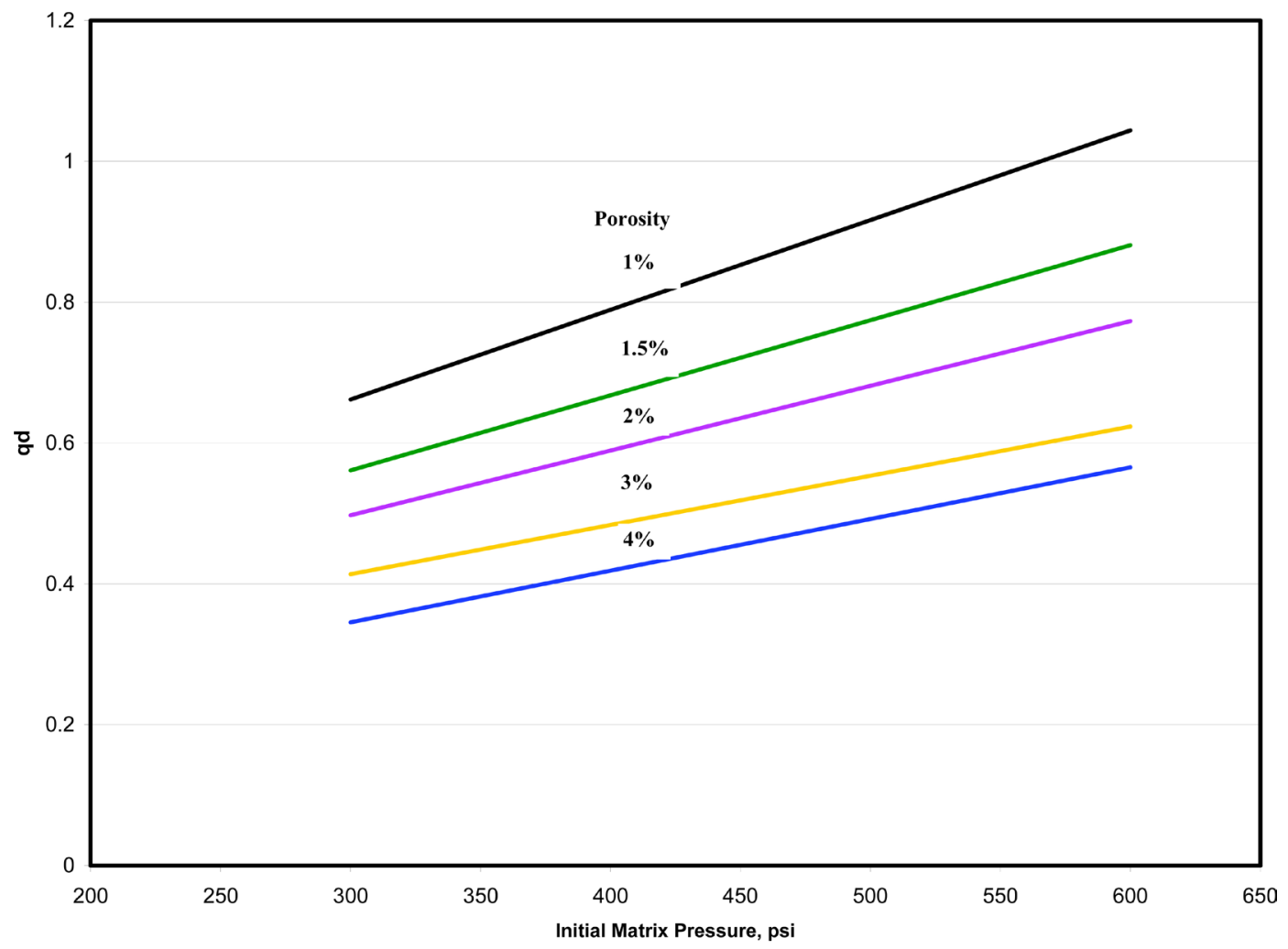

Figure 4. Correlation among dimensionless peak gas rate, porosity, and initial matrix pressure [17]. 
- Determination of parameters: coal saturation, absolute permeability, porosity, compressibility and pore volume.

- Calculation of gas production.

- Optimization of well spacing.

A methodology for the initial estimation of CBM resources and reserves easily extrapolated has been developed. This methodology will serve to determine in what amount the parameters of the reserve should vary to obtain the return on investment. The calculations have been made in Anglo-Saxon units, due to their greater development in calculation methods, and have been converted to international system units later for better handling.

\section{North León basin}

Once the drilling point has been defined, the immediate analysis of the coal is analyzed, and its rank determined. The analysis is corrected in ash, for an ash content of $15 \%$, which is the estimated content in the layer. The analysis of ash-free dry coal, which will be used in later calculations, is also corrected.

Once this is done, the gas content of the target layer is extracted, and is expressed in gross ton, tb (15\% ash) and dry ton free of ash or pure ton (dry ash free -daf) as shown in Table 7.

Table 8 shows coal saturation. This is calculated based on the gas in situ (GIS) and the geological conditions:

With this gas content and the pressures valued, the coal saturation is $129.29 \%$. The coal is oversaturated, $29 \%$ of the contained gas is free. This is due to the lower coal rank.

The recoverable gas and resulting factors are shown in Table 9. Coal is estimated to have an adsorbed gas content of around $4.25 \mathrm{~m}^{3} / \mathrm{t}$ daf, which corresponds

Table 7. North Leon coal proximate analysis [5].

\begin{tabular}{cccc}
\hline & Coal proximate analysis available & Coal analysis with $15 \%$ ash & Dry ash free \\
\hline C fixed (\%) & 46 & 50 & 66.50 \\
Humidity (\%) & 14 & 18 & 0 \\
Ash (\%) & 27 & 15 & 0 \\
Volatile (\%) & 13 & 17 & 33.50 \\
Rank & & Bituminous high volatiles \\
\hline
\end{tabular}

Table 8. North Leon basin coal saturation.

\begin{tabular}{cccc}
\hline Coal saturation N Leon & & & \\
\hline GIS & 8.34 & $\mathrm{~m}^{3} / \mathrm{t}$ bulk & GIS \\
GIS & 12.45 & $\mathrm{~m}^{3} / \mathrm{t} \mathrm{daf}$ & GIS \\
Depth & 900 & $\mathrm{~m}$ & Depth \\
GIS máx Eddy & 340 & $\mathrm{cf} / \mathrm{t} \mathrm{daf}$ & GIS máx Eddy \\
GIS máx Eddy & 9.63 & $\mathrm{~m}^{3} / \mathrm{t}$ & GIS máx Eddy \\
Saturation & 129.29 & $\%$ & Saturation \\
\hline
\end{tabular}


to a recovery of more than $65 \%$ of the gas it contains. Of this $65 \%$ maximum recoverable, $22 \%$ of the total would be recoverable as free gas and $43 \%$ as adsorbed gas.

This coal is considered permeable with an absolute permeability of $5.40 \mathrm{mD}$ being observed. This magnitude will facilitate production and increase the spacing of the wells.

\section{Guardo-Barruelo basin}

The coal of the Barruelo area has a gas quantity of $12.1 \mathrm{~m}^{3} / \mathrm{t}$. It is therefore considered high bituminous in volatile. The drilling will be carried out at a depth of approximately $800 \mathrm{~m}$. The characteristics of the coal are shown in Table 10.

Correcting the values for the ash content and comparing this value with the maximum amount of gas adsorbed in that area, you get the saturation percentage of the coal. This is shown in Table 11.

Table 9. Recoverable gas N Leon.

\begin{tabular}{ccc}
\hline Recoverable gas N Leon & & \\
\hline Initial fracture pressure & 1272 & psi \\
Initial matrix pressure & 725 & psi \\
Minimum desorption pressure & 237 & psi \\
Pressure fractures final & 75 & psi \\
Final GIS Eddy & 150 & cf/t pure \\
Final GIS Eddy & 4.25 & $\mathrm{~m}^{3} / \mathrm{t}$ pure \\
Recoverable percentage & 65.88 & $\%$ \\
Free recoverable percentage & 22.66 & $\%$ \\
Recoverable percentage desorbed & 43.22 & $\%$ \\
\hline
\end{tabular}

Table 10. Guardo-Barruelo coal proximate analysis [5].

\begin{tabular}{cccc}
\hline & Coal. Immediate analysis available & Coal analysis with $15 \%$ ash & Dry ash free \\
\hline C fixed (\%) & 39.20 & 46.53 & 61.40 \\
Humidity (\%) & 7.40 & 14.73 & 0 \\
Ash (\%) & 37.00 & 15.00 & 0 \\
Volatile (\%) & 16.40 & 23.73 & 38.60 \\
Rank & & Bituminous high volatiles \\
\hline
\end{tabular}

Table 11. Guardo-Barruelo basin coal saturation.

\begin{tabular}{ccc}
\hline & Coal saturation Guardo-Barruelo & \\
GIS & 12.10 & $\mathrm{~m}^{3} / \mathrm{t} \mathrm{bulk}$ \\
GIS & 17.22 & $\mathrm{~m}^{3} / \mathrm{t} \mathrm{daf}$ \\
Depth & 800 & $\mathrm{~m}$ \\
GIS máx Eddy & 300.00 & $\mathrm{cf} / \mathrm{t} \mathrm{daf}$ \\
GIS máx Eddy & 8.49 & $\mathrm{~m} 3 / \mathrm{t}$ \\
Saturation & 202.71 & $\%$ \\
\hline
\end{tabular}


Coal is supersaturated, since the amount of gas that the coal can contain adsorbed under the conditions of the reserve is lower than that contained in the analyses, which explains the existence of free gas according to operating references in the area.

The next stage determines the calculation of the initial pressure of the matrix and of the fractures. The initial pressure of the fractures is established as a function of depth, and the initial pressure of the matrix is related to it. From the Eddy curve, a minimum desorption pressure is estimated, which will be the pressure of the fractures at which the coal will begin to desorbed gas.

In Table 12, there is the calculation of the maximum recoverable gas of the layer, which due to its over-saturation conditions will be higher than in the North of León. Finally the production expected is shown in Figure 5.

\section{Economic Feasibility of the North Leon Basin Pilot Well}

The funds for the development of the project will be own funds, so the request

Table 12. Recoverable gas Guardo-Barruelo.

\begin{tabular}{ccc}
\hline Recoverable gas N Leon & & \\
\hline Initial fracture pressure & 1131 & $\mathrm{psi}$ \\
Initial matrix pressure & 644.69 & $\mathrm{psi}$ \\
Minimum desorption pressure & - & $\mathrm{psi}$ \\
Pressure fractures final & 75 & $\mathrm{psi}$ \\
Final GIS Eddy & 160 & $\mathrm{cf} / \mathrm{t}$ pure \\
Final GIS Eddy & 4.53 & $\mathrm{~m}^{3} / \mathrm{t}$ pure \\
Recoverable percentage & 73.69 & $\%$ \\
Free recoverable percentage & 50.67 & $\%$ \\
Recoverable percentage desorbed & 23.02 & $\%$ \\
\hline
\end{tabular}

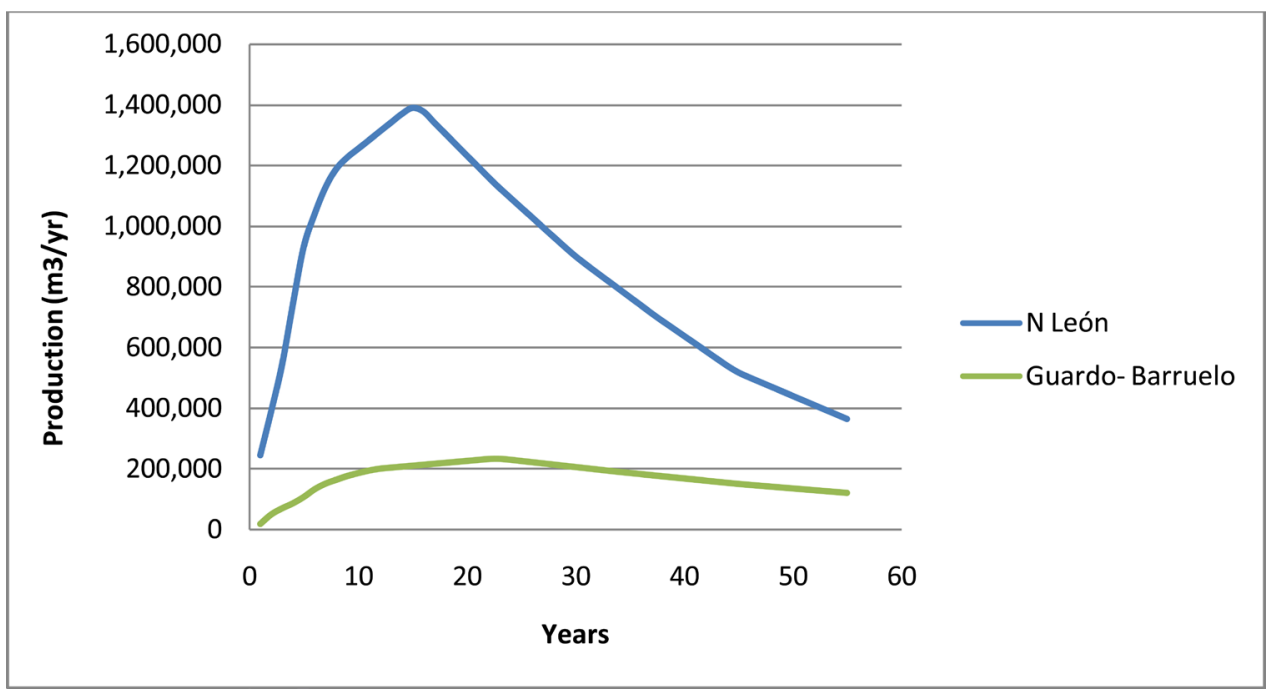

Figure 5. Production CBM pilot wells N León and Barruelo. 
for loans for the development of the project is not taken into account. The intrinsic profitability of the project will be valued (IRR $<0 \%$ ), but in addition it will consider the possibility of obtaining a yield higher than that which would be obtained for a fixed term of those equity at $4 \%$, which will require some parameters of recovery different, and a return of $8 \%$ that will also integrate the uncertainty of the investment.

As we have seen, the pilot well of the North of León is the one that yields the highest production. The fixed costs will be the same for the development of the project at any time, while the variable costs will be higher in the North of León Basin than in Guardo-Barruelo basin. The following is detailed: the production in $\mathrm{m}^{3}$ of gas from the well, the sum total of annual fixed costs, where in the first year the investment of the well drilling is considered, the variable expenses broken down into capture and transport of natural gas, and a sum of the total costs for fifty years of life the well.

The next step is to know the annual income for each one of the scenarios contemplated and the cost-revenue difference.

With these data, the cash flows for each of the scenarios analyzed could be represented as follows. The graph clearly shows the great influence of gas prices on incomes, as one might think at first.

By making a NPV analysis of the project for different discount rates depending on the scenario, we obtain the following graphs. In them you can see how the NPV of the project is larger the longer the exploitation lasts and with a lower discount rate. Analyzes have been carried out with the active well 10,20, 30 and 50 years, in order to know their values according to the various life stages of the well. The results are shown in Figure 6.

If we set the discount rate at $10 \%$ and analyze the NPV for the different scenarios with respect to time, we observe how the project gains assets during the years, very quickly and then stabilizes, so the project will be more profitable the more years the well remains active, since up to 50 years the costs that are generated are always covered with the income. In addition, the sensitivity of the NPV can be observed under the different scenarios. Scenario 4 triples the NPV after 25 years of exploitation. The project is very sensitive to the sale prices of gas in the wholesale market. The strong point is that traditionally the price of natural gas has increased very clearly, with the prospects happening because it continues to do so, an upward trend that will improve the economic viability of the project. The profitability of the project is analyzed according to the IRR or internal rate of return. The results obtained are summarized in the following Table 13.

The pilot well shows a high profitability. It would be profitable in the worst case scenario, 10 years of well life and $25 \%$ lower gas prices. When gas prices rise, profitability also does so, standing at $45 \%$ for 30 and 50 years, so the business is revealed as attractive. Considering $8 \%$ as the minimum return to make the investment attractive, the survey is profitable and can be carried out. 

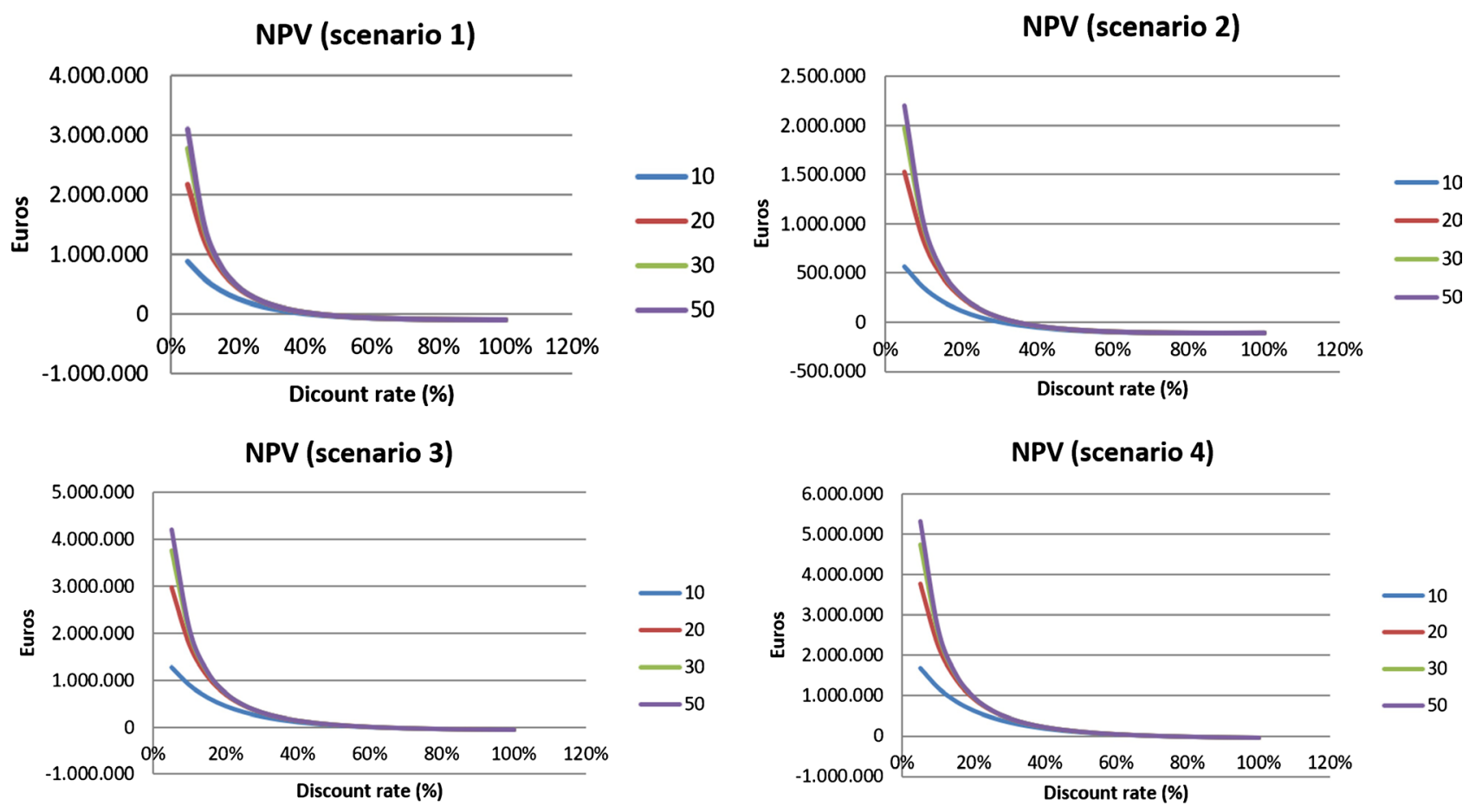

Figure 6. NPV for North León basin for different scenario in 10, 20, 30 and 50 years.

Table 13. Internal rate of return $\mathrm{N}$ Leon basin

\begin{tabular}{|c|c|c|c|c|}
\hline \multicolumn{5}{|c|}{ Internal rate of return, IRR } \\
\hline Year & Scenario 1 & Scenario 2 & Scenario 3 & Scenario 4 \\
\hline 10 & $42 \%$ & $30 \%$ & $57 \%$ & $73 \%$ \\
\hline 20 & $45 \%$ & $35 \%$ & $59 \%$ & $74 \%$ \\
\hline 30 & $45 \%$ & $35 \%$ & $59 \%$ & $74 \%$ \\
\hline 50 & $45 \%$ & $35 \%$ & $59 \%$ & $74 \%$ \\
\hline
\end{tabular}

\section{Economic Feasibility of the Guardo-Barruelo Basin Pilot Well}

As we have analyzed, the sounding of the Guardo-Barruelo zone presents lower production than the previous one. The fixed costs will be the same for the development of the project at any time, while the variables will be higher in the North of León. The following is detailed: the production in $\mathrm{m}^{3}$ of gas from the survey, the total sum of annual fixed costs, (where in the first year the investment of the well drilling is considered) the variable costs of capturing and transporting natural gas, and a sum of the total costs for 50 years of life the well.

The cash flows for scenarios 1 and 4 are analyzed with respect to time. In scenario 1, operating and maintenance expenses are barely covered. Only between years 15 and 30 of the well's life can we obtain small annual benefits, but the NPV of the project for scenario 1 will always be lower, so it will not be considered profitable.

In scenario 4 we would cover costs during the years 7 to 49 . The economic vi- 
ability increases under this scenario and the IRR of the project becomes positive under certain circumstances as we will see later.

By making a NPV analysis of the project for different discount rates depending on the scenario, we obtain the following graphs. In them it can be seen how the NPV of the project varies according to the discount rate, but it does not seem to be very sensitive to the exploitation time except for scenario 4. Analyses have been carried out with active well 10, 20, 30 and 50 years, to be able to know their values in function of the diverse states of life of the well. The results are shown in Figure 7.

The results for IRR are shown in Table 14. The well is only profitable, at $0 \%$ annual rate, in scenario 4 to 30 and 50 years, presenting negative values in the rest of the cases. Therefore, it could currently be considered as a reserve but not as a resource, since extraction is still not profitable.

\section{Conclusions}

Once the technical feasibility of the CBM extraction of Castilla y León was analyzed,
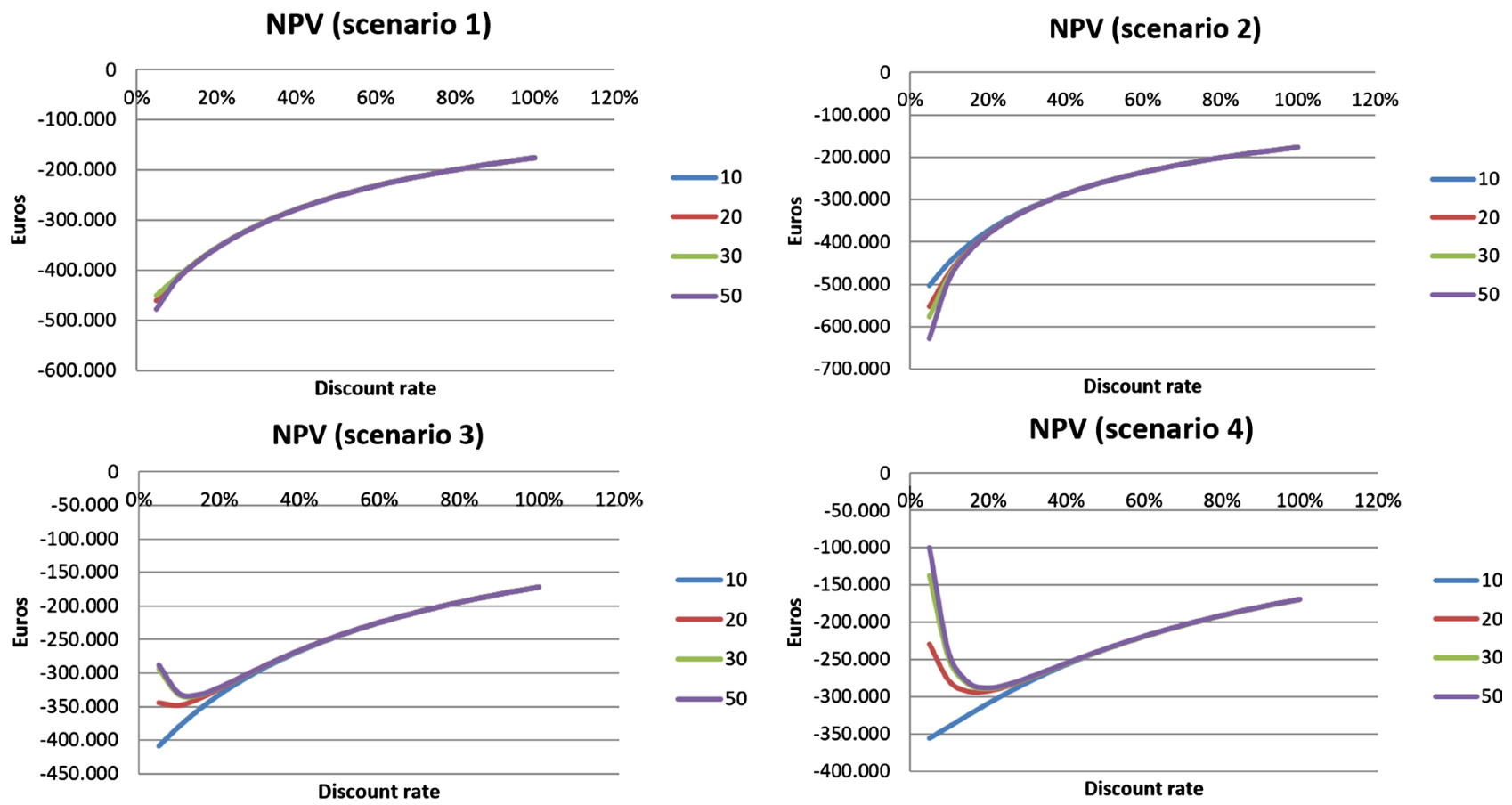

Figure 7. NPV for Guardo-Barruelo basin for different scenario in 10, 20, 30 and 50 years.

Table 14. Internal rate of return Guardo-Barruelo basin.

\begin{tabular}{ccccc}
\hline \multicolumn{5}{c}{ Internal rate of return, IRR } \\
\hline Year & Scenario 1 & Scenario 2 & Scenario 3 & Scenario 4 \\
\hline 10 & - & - & - & - \\
20 & - & - & - & $-2 \%$ \\
30 & - & - & - & $2 \%$ \\
50 & - & - & - & $3 \%$ \\
\hline
\end{tabular}


the next step was the realization of an economic viability analysis.

The next step was the calculation of the economic viability itself for the two proposed surveys, with different results. While the survey of the North of Leon area presented a positive economic viability in almost any circumstance, the Guardo-Barruelo sounding would be profitable, with IRR $>0 \%$, only in certain circumstances.

The economic viability was calculated with three different profitability objectives for positive evaluation. The first one only contemplates the recovery of the investment (IRR $>0 \%$ ), while the second and third raise the possibility of obtaining more return than an investment of $4 \%$ and $8 \%$. For these projections, four possible scenarios were considered of natural gas price in the wholesale market: the current price (scenario 1), price reduction by $25 \%$ (scenario 2), price increase by $25 \%$ (scenario 3 ) and price increase $50 \%$ (scenario 4 ).

For the estimation of the economic viability, in a first stage, the annual production of each well was determined and, after this, the annual investment and operation costs. Next, revenues were defined for each of the proposed scenarios and profitability was analyzed for each case.

The recoverable gas in a profitable manner depends on the required profitability design conditions and gas prices. Combining the returns and gas prices studied, up to twelve cases can be obtained for 30 years of production.

The future lines of research would be related in the first place to the validation of the theoretical and experimental methods detailed in this document using field data obtained from real surveys. This would also serve to adjust the model for feasibility of the projects described.

Another point to be developed in the future, once the well behavior data is known, will be the possible use of some layers for ECBM (Enhanced Coalbed Methane) production. What has been seen reports numerous economic and environmental benefits. In addition, a detailed study of the storage capacity of $\mathrm{CO}_{2}$ in the coal layers of Castilla y León could be carried out.

The results and conclusions of this work will serve to increase the knowledge of the coal basins of Castilla y León, and its key parameters, useful for other uses, how could be the underground gasification of coal, which can be combined with the storage of $\mathrm{CO}_{2}$ getting another zero emissions technology.

\section{Conflicts of Interest}

The authors declare no conflicts of interest regarding the publication of this paper.

\section{References}

[1] Creedy, D.P. (2001) A Review of the Worldwide Status of Coalbed Methane Extraction and Utilisation. Department of Trade and Industry's Cleaner Coal Technology Transfer Programme, ETSU.

[2] Dong, J. (2015) Coal Mine Methane Control Cost and Full Cost: The Case of the Luling Coal Mine, Huaibei Coalfield, China. Journal of Natural Gas Science and 
Engineering, 26, 290-302.

[3] IEA CCC. (2006) Power Projects Using Methane from Coal Mines.

[4] Creedy, D. and Tilley, H. (2003) Coalbed Methane Extraction and Utilization. Proceedings of the Institution of Mechanical Engineers, Part A: Journal of Power and Energy, 217, 19-25.

[5] IGME. (1995) Actualización del Inventario de Recursos Nacionales de Carbón: Guardo-Barruelo.

[6] Aitemin. (2000) Drenaje y desgasificación de grisú en capas de carbón potentes y verticales explotadas por subniveles horizontales con sutiraje. Memoria 1999. Madrid, España, 27-28.

[7] Aitemin. (2000) Reducción de la contaminación medioambiental producida por las emisiones de metano en minas abandonadas. Memoria 1999. Madrid, España, 41-42.

[8] IEA. (2018) International Energy Outlook.

[9] Boyer, C. (2004) Understanding the Impact of Technology on Full Cycle CBM Financial Viability. The Successful Commercialization of Global Coalbed and Coalmine Methane Projects, London.

[10] US DOE. (2006) The Economics of Powder River Basin Coalbed Methane Development. Advanced Resources International, Inc.

[11] Eddy, G.E. (1982) Relationship of Methane Content of Coal Rank and Depth: Theoretical vs. Observed. Proceedings of the SPE Unconventional Gas Recovery Symposium, Pittsburgh, 16-18 May 1982. https://doi.org/10.2118/10800-MS

[12] Gray, I. (1987) Reservoir Engineering in Coal Seams, the Physical Process of Gas Storage and Movement in Coal Seams. SPE 12514, Reservoir Engineering, 28-40.

[13] Laubach, S.E. (1997) Characteristics and Origins of Coal Cleat: A Review. International Journal of Coal Geology, 35, 175-207.

[14] Cardott, B.J. (2001) Coalbed Methane Activity in Oklahoma 2001. Oklahoma Coalbed-Methane Workshop: Oklahoma Geological Survey, Open-File Report of 2-2001, 93-139.

[15] Weniger, S., et al. (2016) Characterizing Coal Cleats from Optical Measurements for CBM Evaluation. International Journal of Coal Geology, 154-155, 176-192. https://doi.org/10.1016/j.coal.2015.12.005

[16] Gas Research Institute. (1991) Coalbed Methane of Western North America: Guidebook for the Rocky Mountain. Association of Geologists Fall Conference and Field Trip, 17-20 September, Glenwood Springs, Colorado.

[17] Arenas, G. (2004) Development of Gas Production Type Curves for Coalbed Methane Reservoirs. Department of Petroleum and Natural Gas Engineering of West Virginia. 